Nubia Garcia Vianna ${ }^{1}$

Maria de Lourdes Tavares Cavalcanti ${ }^{2}$

Moab Duarte Acioli ${ }^{3}$

\title{
Princípios de universalidade, integralidade e equidade em um serviço de atenção à saúde auditiva
}

Principles of universality, comprehensiveness and equity in a hearing health care service

Moab Duarte Acioli

${ }^{1}$ Centro de Estudos e Pesquisas em Reabilitação Prof Dr. Gabriel O. S. Porto, Universidade Estadual de Campinas. R. Tessália Vieira de Camargo 126, Barão Geraldo. 50.100-130 Campinas SP Brasil. nubiagvianna@gmail.com ${ }^{2}$ Instituto de Estudos em Saúde Coletiva,

Universidade Federal do Rio de Janeiro

${ }^{3}$ Centro de Ciências

Biológicas e da Saúde,

Universidade Católica de

Pernambuco.
Abstract This article analyzed whether the practices of hearing health care were consistent with the principles of universality, comprehensiveness and equity from the standpoint of professionals. It involved qualitative research conducted at a Medium Complexity Hearing Health Care Center. A social worker, three speech therapists, a physician and a psychologist constituted the study subjects. Interviews were conducted as well as observation registered in a field diary. The thematic analysis technique was used in the analysis of the material. The analysis of interviews resulted in the construction of the following themes: Universality and access to hearing health, Comprehensive Hearing Health Care and Hearing Health and Equity. The study identified issues that interfere with the quality of service and run counter to the principles of Brazilian Unified Health System. The conclusion reached was that a relatively simple investment in training and professional qualification can bring about significant changes in order to promote a more universal, comprehensive and equitable health service.

Key words Health care, Public health, Hearing loss
Resumo O objetivo do presente estudo foi analisar se as práticas de atenção à saúde auditiva estavam coerentes com os princípios da universalidade, da integralidade e da equidade sob a perspectiva dos profissionais. Pesquisa qualitativa, realizada em um Serviço de Atenção à Saúde Auditiva de Média Complexidade. Constituíram sujeitos: uma assistente social, três fonoaudiólogas, uma médica e uma psicóloga. Foram realizadas entrevistas, bem como observação com registro em diário de campo. Na análise do material foi utilizada a técnica de análise temática. A análise das entrevistas resultou na construção dos seguintes temas: A Universalidade e o Acesso à Saúde Auditiva, Atenção Integral à Saúde Auditiva e Saúde Auditiva e Equidade. O trabalho apontou questões que comprometem a qualidade do serviço e que ferem os princípios do SUS. Conclui-se que investimentos relativamente simples em capacitação e qualificação profissional podem trazer mudanças significativas no sentido de propiciar a prestação de um serviço mais universal, integral e equânime.

Palavras-chave Atenção à saúde, Saúde pública, Deficiência auditiva 


\section{Introdução}

A atenção à saúde da pessoa com deficiência no Brasil é legitimada na Constituição de $1988^{1}$, em seu artigo 23 que afirma ser de competência da União, dos Estados, do Distrito Federal e dos Municípios, a responsabilidade pelo cuidado à saúde e assistência pública, proteção e garantia das pessoas com deficiência. São consideradas pessoas com deficiência as que apresentam algum impedimento físico, mental ou sensorial associado às barreiras para a inclusão existentes na sociedade, ou as que têm limitações que impossibilitam suas participações plenas como cidadãos no meio em que vivem ${ }^{2}$.

Uma das deficiências sensoriais que mais vem crescendo no Brasil e no mundo refere-se à auditiva. Nesse sentido, em 2004, foi criada a Política Nacional de Atenção à Saúde Auditiva (PNASA) por meio da Portaria no $2.073 / 04^{3}$ levando em consideração os princípios do Sistema Único de Saúde (SUS) estabelecidos na lei no 8.080/904. Estes são: universalidade de acesso aos serviços de saúde em todos os níveis de atenção; integralidade de assistência, compreendida como um conjunto de ações e serviços preventivos e curativos, individuais e coletivos, que devem funcionar de forma articulada em todos os níveis de atenção; e igualdade da assistência à saúde, sem preconceitos ou privilégios de qualquer natureza. Posteriormente, o termo equidade passou a ser utilizado em lugar de igualdade ${ }^{5}$.

Desde o surgimento do SUS, tem se buscado incorporar os princípios doutrinários de universalidade, integralidade e equidade como elementos norteadores de todas as políticas públicas de saúde. Nesse contexto, a PNASA visou atender às demandas de avaliação, diagnóstico e (re)habilitação com o auxílio de recursos tecnológicos, como os aparelhos auditivos, dirigidos às pessoas com essa deficiência. Deve-se comentar que essa Política não se limitou ao caráter reabilitador, como a maioria das portarias publicadas na década de 90 , que se restringiam ao fornecimento de aparelhos auditivos e à colocação de implantes cocleares, apesar da Lei n. ${ }^{\circ} 7.853 /$ $89^{6}$ e do Decreto 3.298/997 já terem indicado a importância de ações de promoção e proteção à saúde auditiva. Esta Política contemplou, pela primeira vez no cenário da saúde, ações de promoção da saúde auditiva e de prevenção de problemas que cursassem com alterações auditivas. Para tanto, foram previstas ações na Atenção
Básica, na Média e na Alta Complexidade. Isto significa que com a PNASA surgiu uma abordagem mais ampla e diferente de todas as portarias relacionadas à saúde auditiva que existiam até 2004, mesmo que na realidade dos serviços as novas ações propostas fossem difíceis de ser operacionalizadas. Diante deste quadro, Fabrício ${ }^{8}$ afirma que para se observarem mudanças de qualidade nos serviços de saúde, ainda há muito por fazer, visto que o monitoramento das políticas tem sido insuficiente.

Certamente o SUS, pautado pelos princípios de universalidade, integralidade e equidade, favorece a formulação de políticas voltadas para as pessoas com deficiência de modo a atendê-las em suas necessidades. No entanto, apesar dos avanços na ampliação do acesso e da cobertura de serviços ${ }^{9}$, ainda permanece a distância entre as práticas de saúde e os princípios instituídos, especialmente no que diz respeito aos grupos minoritários ou portadores de necessidades especiais. Assim, considera-se pertinente o estudo de um serviço específico de saúde auditiva a fim de contribuir para o planejamento, fornecendo elementos para melhorar a estruturação e a adequação do atendimento às necessidades dos usuários.

Dessa forma, o presente artigo teve como objetivo analisar se as práticas de atenção à saúde auditiva em um serviço especializado estavam coerentes com os princípios da universalidade, da integralidade e da equidade sob a perspectiva dos profissionais.

Com esse intuito, o acesso ao cuidado auditivo foi utilizado como parâmetro na abordagem da universalidade. A integralidade foi enfocada como superação da fragmentação do cuidado individual e articulação das ações e serviços necessários nos diferentes níveis de complexidade do sistema. E a equidade foi examinada na perspectiva da igualdade em saúde, compreendida como a noção de que todos os indivíduos de uma sociedade devem ter justa oportunidade para desenvolver seu pleno potencial de saúde e, no aspecto prático, ninguém deve estar em desvantagem para alcançá-lo ${ }^{10}$.

Sendo assim, para haver igualdade é necessário reconhecer que há diferenças e que, em função disso, devem existir formas de tratamento distintas para cada situação que se apresente ${ }^{5}$. Nesse sentido, no âmbito das políticas públicas, equidade se traduz em igualdade com respeito à diversidade e redução das desigualdades sociais consideradas injustas. 
Métodos

Esta é uma pesquisa qualitativa de base exploratória. Foi realizada em um Serviço de Atenção à Saúde Auditiva de Média Complexidade localizado em um Centro Municipal de Saúde do Rio de Janeiro, no período de agosto a outubro de 2009. Esse Serviço fazia parte da Rede de Atenção à Saúde Auditiva do Estado do Rio de Janeiro, composta por quatorze unidades ${ }^{11}$ na época do estudo.

Foram selecionados como sujeitos da pesquisa, uma assistente social, três fonoaudiólogas, uma otorrinolaringologista e uma psicóloga do serviço estudado. Todos profissionais pertencentes às categorias previstas na Portaria ${ }^{\circ}$ $587 / 04^{12}$ que normatiza e regulamenta a PNASA.

A coleta de dados ocorreu por meio de entrevista semiestruturada e observação dirigida, cujos instrumentos de trabalho foram o roteiro de entrevista e o diário de campo.

Os critérios de observação consistiram nos fatos e circunstâncias presentes na dinâmica da unidade e relacionados ao problema em estudo, sendo eles registrados em um diário de campo. As entrevistas foram gravadas, transcritas, categorizadas e analisadas, com base na Análise de Conteúdo definida por Bardin ${ }^{13}$ como sendo:

Um conjunto de técnicas de análise de comunicação visando obter, por procedimentos sistemáticos e objetivos de descrição do conteúdo das mensagens, indicadores (quantitativos ou não) que permitam a inferência de conhecimentos relativos às condições de produção/recepção destas mensagens.

Foi utilizada a técnica de análise temática da fala dos sujeitos entrevistados. A análise temática, considerada a mais adequada para pesquisas de cunho qualitativo em saúde, é realizada a partir da descoberta dos núcleos de sentido presentes em uma comunicação, devendo se observar também a frequência de seus aparecimentos. $\mathrm{O}$ conceito de tema fundamenta-se na noção de núcleo de uma determinada ideia ${ }^{14}$.

A pesquisa teve aprovação do Comitê de Ética e Pesquisa da Secretaria Municipal de Saúde e Defesa Civil do Rio de Janeiro. Os sujeitos participantes foram esclarecidos sobre a proposta, verbalmente e através do Termo de Consentimento Livre e Esclarecido, sendo este assinado por todos os sujeitos.

\section{Resultados e discussão}

A análise das entrevistas resultou na construção dos seguintes temas: A) Universalidade e o Aces- so à Saúde Auditiva B) Atenção Integral à Saúde Auditiva; C) Saúde Auditiva e Equidade.

\section{A) Universalidade}

e o acesso à saúde auditiva

Retomando o conceito de universalidade como sendo o acesso ao serviço de saúde em todos os níveis de atenção, observa-se que o cuidado do paciente com demandas auditivas é previsto na Portaria SAS/MS no $587 / 04^{12}$ e deve ser realizado por uma equipe multiprofissional formada por: assistente social, fonoaudiólogos, médico e psicólogo. Para tanto, estão previstas ações de avaliação audiológica, indicação, seleção e adaptação de aparelho de amplificação sonora individual, bem como de terapia fonoaudiológica o que foi constatado acontecer no serviço estudado, porém, podem-se destacar algumas dificuldades para a realização destes procedimentos.

O serviço dispunha de quase todos os materiais e equipamentos necessários para realização de tais ações, entretanto, foram observados problemas técnicos nos equipamentos e interrupção quanto ao recebimento dos aparelhos auditivos. $\mathrm{Na}$ visão dos profissionais, isso limita e até impede o funcionamento do serviço dificultando o acesso à atenção à saúde auditiva. $\mathrm{O}$ relato abaixo evidencia este problema.

A gente está com muitos problemas. Equipamentos com problema. Não são problemas difíceis de solucionar, são problemas fáceis. [...] a gente também não está recebendo prótese. A última remessa de prótese que nós recebemos foi no ano passado. A compra de novos aparelhos está em licitação. (Fonoaudióloga 3)

Tais problemas são descritos como de fácil solução, mas se tornam difíceis, pois para resolvê-los é necessário que os serviços se submetam a trâmites extremamente burocráticos. Para exemplificar, um dos entrevistados, sabendo da demora que haveria para que o serviço repusesse uma peça de um dos equipamentos necessários para avaliação auditiva, decidiu comprá-la com seu próprio dinheiro.

Uma pesquisa realizada por Amaral e Gui$\operatorname{lan}^{15}$ apontou que o serviço de Saúde Auditiva onde foi realizado o trabalho apresentava problemas semelhantes, visto que nem todos os equipamentos estavam em condições adequadas de funcionamento.

Em segundo lugar, a etapa seguinte ao processo de protetização se refere à terapia fonoaudiológica que tem enfoques diferentes dependendo, principalmente, do momento em que a per- 
da auditiva surgiu na vida do paciente e qual o impacto trazido por ela. No caso de crianças que nasceram com perda auditiva, isso pode dificultar ou impedir o desenvolvimento da linguagem oral haja vista a importância que os estímulos sonoros têm nesse processo ${ }^{16}$. Esta condição requer uma terapia fonoaudiológica que tenha como objetivo promover a aquisição e o desenvolvimento da linguagem.

Por outro lado, quando a perda auditiva aparece em um momento posterior ao desenvolvimento da linguagem, a terapia fonoaudiológica tem objetivos diferentes, com foco na capacitação do sujeito para a utilização de estratégias que agregadas ao uso do aparelho auditivo potencializam a comunicação, tais como a leitura orofacial. Nessas circunstâncias, a terapia fonoaudiológica é necessária, pois o uso exclusivo do aparelho auditivo não é suficiente para resolver os impactos de uma perda auditiva.

No entanto, pelo relato dos profissionais, percebeu-se que a (re)habilitação, em função da escassez de vagas para terapia, muitas vezes tem fim simplesmente com a colocação do aparelho auditivo. Ianni e Pereira ${ }^{17}$ estudaram as peculiaridades do acesso da população surda aos serviços de atenção básica constatando a carência de profissionais para reabilitação. Por sua vez, Amaral e Guilan ${ }^{15}$ encontraram reduzido número de atendimento fonoaudiológico para adultos e idosos no setor de reabilitação de um serviço de saúde auditiva, o que prejudica uma adequada adaptação ao aparelho auditivo. Observou-se o mesmo no presente estudo: em virtude da falta de vagas são priorizados os atendimentos de crianças em detrimento dos adultos, como exposto a seguir.

[...] depois [de protetizado], se for adulto, tendo a vaga, a gente encaixa na terapia. O ideal seria que todos passassem pela terapia [...] O ideal seria que todos tivessem um acompanhamento terapêutico [...] só que isso é inviável e impossível. (Fonoaudióloga 1)

A fala acima expressa a consciência do profissional quanto à necessidade de terapia após a colocação do aparelho auditivo, para garantir uma reabilitação bem sucedida. No entanto, o serviço está organizado em função de prioridades e, como as crianças estão em processo de desenvolvimento, a ausência da terapia comumente traz mais danos para elas do que para os adultos.

O foco no aparelho auditivo em detrimento de vagas para terapia é contraditório e merece destaque, visto que quanto mais se oferece aparelho mais se demandam ações de terapia fonoaudiológica para assegurar o uso eficaz do equipamento. Há um desequilíbrio de esforços e de recursos aplicados nas ações de atenção à saúde auditiva que priorizam os gastos com o aparelho auditivo, sem um comprometimento rigoroso com a utilização correta deste.

As ações previstas na PNASA para o cuidado dos usuários do serviço fazem parte das práticas de saúde conduzidas pelos profissionais e mediadas pelo diálogo, como deve ser em qualquer serviço de saúde. No entanto, por se tratar de um serviço de saúde auditiva é mais comum aparecerem usuários surdos que se comunicam por meio da língua brasileira de sinais (Libras), que tem sua estrutura linguística caracterizada por ser visual-gestual, ou seja, sujeitos que apresentam uma identidade construída por acessar o mundo essencialmente pela experiência visual ${ }^{18}$.

Contudo, uma queixa que apareceu em todas as entrevistas foi a de que o serviço não estava preparado para atender a esses usuários, uma vez que, apenas um dos profissionais do serviço fazia uso de Libras. Este fato ajuda a entender porque havia poucos surdos atendidos no serviço, ou seja, a barreira de acesso decorrente da dificuldade de comunicação entre profissionais e usuários pode ser um dos motivos da escassez de pessoas que se comunicam por língua de sinais entre os usuários do serviço.

A assistente social, por desconhecer a língua de sinais, relatou não atender a pacientes surdos que se comunicassem por Libras, exceto se estivessem acompanhados de familiares ou de uma fonoaudióloga que pudessem auxiliar na comunicação. Isso alimenta a dependência deste paciente para com uma terceira pessoa, geralmente, um parente, amigo ou até mesmo do intérprete.

É um problema [a comunicação com usuários surdos]. Porque eu tenho dificuldade de entender. Eu ainda não estou podendo atender esses casos. A pessoa que é completamente surda, no momento, eu ainda não estou atendendo porque eu sinto dificuldade de entendimento. Só se tiver acompanhado de alguém, um familiar, amigo. (Assistente social)

A ausência do intérprete nos serviços de saúde constitui uma barreira comunicacional ${ }^{17}$, mas, por outro lado, outros autores ${ }^{19}$ mostraram que a presença do intérprete pode melhorar, mas não é decisiva para um atendimento de qualidade. É comum, nos casos em que a comunicação é mediada pelo intérprete, que o surdo apresente a sensação de constrangimento e desconfiança na presença do mesmo ${ }^{19,20}$.

A psicóloga, que já desempenhava outras funções na unidade de saúde, mencionou durante a 
entrevista, possuir escasso conhecimento no trabalho com surdos e não ter capacitação em língua de sinais o que prejudica a interação profissional-usuário surdo inviabilizando qualquer projeto terapêutico. Por essa razão, ela demonstrou indignação por sua lotação neste serviço.

Tanto a psicóloga quanto a assistente social recusaram-se a cumprir uma lógica de funcionamento imposta pelo serviço, que para se credenciar junto ao Ministério da Saúde, tem que ter profissionais dessas duas categorias. Para o serviço, ter psicóloga e assistente social significa o cumprimento de uma obrigação legal, mas para elas terem sido lotadas neste serviço significa um compromisso ético com o mesmo e, por conseguinte, com os usuários. Para tanto, elas apontaram a necessidade de capacitarem-se tecnicamente, inclusive, no aprendizado da língua de sinais. Uma análise superficial poderia levar a pensar no estereótipo de funcionário público que não quer nada, mas o que se vê aqui é justamente o contrário, ou seja, profissionais comprometidas não só com a técnica, mas também com a ética envolvida no processo de cuidar.

Ainda com relação à dificuldade comunicacional existente entre surdos e profissionais, os sujeitos entrevistados reconheceram que algo precisava ser feito para resolver o problema. A maioria dos profissionais fazia uso de recursos como a escrita e a leitura labial, no entanto, comumente, não obtinham sucesso e, quando possível, recorriam à única fonoaudióloga que sabia língua de sinais mas que não trabalhava na unidade todos os dias da semana. Sobre essa observação, pontuou outra profissional:

No dia que a [fonoaudióloga 2] está aqui é ótimo porque os [profissionais] administrativos já levam o paciente até ela e pedem ajuda. Mas e o dia que ela não está? Alguns [usuários] escrevem, mas outros não. Então, o que você faz? Você não consegue se comunicar por Libras, não consegue fazer leitura labial e não dá pra se comunicar pela escrita. Então, isso prejudica bastante. (Fonoaudióloga 3)

Considerando o acesso à atenção auditiva como expressão da universalidade, e tendo em vista que, em princípio, o serviço oferece todas as ações previstas na legislação para a pessoa com essa deficiência, poderia se afirmar existir consonância entre a doutrina e a prática no que diz respeito à atenção a esses pacientes no serviço investigado. No entanto, conforme mencionado pelos profissionais, questões gerenciais (entraves burocráticos que levam à demora na aquisição e reparo de materiais) e de recursos huma- nos (escassez de profissionais e profissionais não capacitados para lidar com pessoas surdas) criam barreiras ao atendimento, seja pela demora na realização dos exames, seja pela falta de próteses, ou pela restrição na oferta de terapia, ou ainda pela dificuldade de comunicação com usuários surdos, resultando na limitação do acesso à atenção auditiva, traduzindo um entrave à universalidade. Esses dois aspectos, a organização dos processos de trabalho e a precariedade de recursos humanos, remetem à complexidade do processo de implantação do SUS, seus nós críticos e impasses estruturais. Menicucci ${ }^{21}$, ao analisar a implementação da reforma sanitária, considera os efeitos das políticas prévias, a frágil sustentabilidade e legitimidade política, fatores determinantes que expõem a ambiguidade da sociedade brasileira na adesão ao SUS, enquanto uma política pública de acesso universal a todos os cidadãos. O apoio formal é insuficiente para garantir a efetivação das ações (financiamento, investimentos e comprometimento) que permanecem aquém do necessário para a efetivação do estabelecido constitucionalmente.

\section{B) Atenção integral à saúde auditiva}

Neste trabalho, considera-se o princípio da integralidade como um conjunto articulado e contínuo de ações e serviços preventivos e curativos como consta na Lei $n^{\circ} 8.080 / 90^{4}$, e abrangendo também o sentido de superação da fragmentação do cuidado, conforme a concepção de Cecílio $^{22}$ que divide a integralidade em duas dimensões: a integralidade "focalizada" e a "ampliada".

Este autor considera que a integralidade "focalizada" acontece na relação entre o profissional ou equipe de saúde e o usuário, ou seja, quando existe o compromisso e a preocupação em resolver as demandas trazidas pelo paciente, por meio de uma escuta atenta e qualificada, inclusive para questões que não estejam claras. Por outro lado, por mais que os serviços busquem atuar na lógica da integralidade "focalizada", por vezes eles não conseguem suprir as demandas apresentadas. Neste momento, a articulação com outros serviços se faz necessária para continuar em busca do agir na integralidade. Esta, portanto, será obtida na medida em que houver uma boa conexão entre os serviços quando estes funcionarem na perspectiva de rede, atingindo uma dimensão "ampliada" de integralidade.

Nesta perspectiva, verificou-se que a dificuldade de comunicação entre profissionais e usuários em função do desconhecimento da Libras, 
além de dificultar o acesso destes prejudica a relação profissional-paciente. Nessas circunstâncias, a interação entre ambos tende a não favorecer a identificação, por parte do profissional, das demandas de ações e serviços de saúde adequadas para cada sujeito.

Chaveiro et al..$^{23}$, em estudo de revisão, concluíram que dificuldades comunicativas podem deteriorar a qualidade do serviço de saúde oferecido. Por sua vez Freire et al. ${ }^{24}$ e Barbosa et al. ${ }^{25}$ afirmaram que, diante da barreira de comunicação existente entre surdos e profissionais de saúde, é indispensável encontrar formas alternativas que garantam uma melhor qualidade da assistência.

Outra questão relevante que fere o princípio da integralidade se refere a um cuidado fragmentado e reducionista, pois o foco das ações recai sobre a ênfase no oferecimento de aparelhos auditivos em detrimento das sessões de terapia fonoaudiológica e dos atendimentos psicológicos e do serviço social. Apesar de o serviço ser composto por uma variedade de profissionais, a atuação entre eles de forma integrada ainda é incipiente como foi comentado pela assistente social.

Quando o problema é de adaptação do aparelho, a gente tem trabalhado em equipe. Eu vou lá, converso com elas [fonoaudiólogas e médica otorrinolaringologista], mas a gente não tem reunião para discutir o caso. Trabalhamos ainda cada um no seu espaço. (Assistente Social).

A fala anterior reforça a necessidade que a equipe tem de reservar momentos para a discussão de casos clínicos, o que favorece a contribuição de diferentes olhares acerca dos problemas dos usuários e uma maior aproximação da resolução dos mesmos. Estes espaços de discussão tendem a evitar que necessidades de saúde sejam ignoradas e, consequentemente, deixem de serem assistidas.

Os profissionais relataram que o cuidado aos pacientes transcende em muito o problema auditivo, pois envolve também questões sociais e emocionais, como mostra o relato abaixo. Isto evidencia a complexidade de fatores que interferem ou ocasionam problemas de saúde nas pessoas, situação não exclusiva da realidade aqui apresentada, mas de todo o campo da saúde coletiva. Isto reforça a necessidade de que as políticas públicas sejam elaboradas de forma intersetorial, bem como a execução das ações provenientes das mesmas.

A gente teve problema com uma criança que nós protetizamos, uma criança que mora num local alagado, numa favela por cima da água, então alaga a casa. [...] Em termos sociais, essa criança não tinha condição de usar um aparelho. [...] Ele já veio com ela (a prótese) quebrada, ela já caiu dentro d'água. (Fonoaudióloga 3 )

[...] a família tem ou não tem estrutura emocional pra realizar protetização da criança agora? Essa família já aceitou que essa criança é surda? (Fonoaudióloga 2)

Pensando no processo de Atenção à Saúde Auditiva de forma ampliada, ou seja, como um conjunto de ações integradas e articuladas, observou-se que no serviço estudado não há, explicitamente, ações de promoção à saúde auditiva $\mathrm{e}$ prevenção de doenças que podem vir a causar problemas auditivos. Os profissionais poderiam desenvolver ações, junto à comunidade, de promoção à saúde auditiva e de prevenção de problemas que possam levar a perda auditiva, em ações articuladas com as equipes de atenção básica. Além disso, poderiam capacitar e atualizar em Saúde Auditiva os profissionais da atenção básica, coordenados pelo gestor local, por meio de cursos, oficinas, jornadas, seminários, encontros locais ou regionais. Junto a isso oferecer suporte técnico às equipes de atenção básica para identificação dos casos que necessitam de encaminhamento para serviços em outros níveis de complexidade; visitar os estabelecimentos onde se encontram estas equipes para discussão de casos clínicos; oferecer avaliação e terapia psicológica, caso o serviço tivesse uma psicóloga de fato; realizar orientação à família e à escola. Embora trabalhos preventivos devam ser aplicados com bastante cautela, para que uma ação de prevenção à saúde não se torne de medicalização, acredita-se que desempenhar ações de prevenção, além de um trabalho assistencial, tornaria o serviço mais próximo do princípio de integralidade do SUS.

A possibilidade de continuidade e permanência a longo prazo, isto é, de êxito, das iniciativas locais, por parte dos profissionais de saúde, depende de intervenções concomitantes nas esferas intermediárias e nacional, advindas dos gestores e formuladores das políticas públicas de saúde. Nesse sentido, com relação às estratégias para integração do cuidado em rede, publicação da Fundação Oswaldo Cruz fruto do Projeto Brasil $2030^{26}$, refere como um desafio a consolidação de um novo modelo de atenção, que articule promoção da saúde, prevenção, tratamento e reabilitação, com fortalecimento da atenção primária e da regionalização em saúde. Segundo o documento:

É possivivel conceber as redes de atenção como uma estratégia de organização da atenção à saúde especificamente voltada para promover a integra- 
ção do cuidado, a partir da combinação entre flexibilidade de alocação de práticas e tecnologias e coordenação do cuidado para a garantia da longitudinalidade do cuidado. Redes de atenção à saúde correspondem a conjuntos de serviços de saúde, de hierarquias recíprocas, com missão e objetivos comuns que se articulam de modo cooperativo e interdependente, para oferecer atenção contínua e integral a determinada população.

Percebendo os desafios que ainda se fazem presentes um dos desdobramentos do Plano Nacional dos Direitos da Pessoa com Deficiência - Viver sem Limites ${ }^{25}$ foi a criação da Rede de Cuidados à Pessoa com Deficiência ${ }^{27}$, que visa implementar serviços e realizar ações estratégicas para atender as necessidades específicas de pessoas com deficiência ${ }^{28}$.

A partir desta rede pretende-se ampliar o acesso e qualificar o atendimento, promover a vinculação das pessoas com deficiência, garantir a articulação e a integração dos pontos de atenção das redes de saúde no território, qualificando o cuidado por meio do acolhimento e classificação de risco ${ }^{27}$. Soma-se a essa iniciativa, o decreto $\mathrm{n}^{\circ}$ $7.508^{29}$ que regulamenta a lei $\mathrm{n}^{\circ} 8.080 / 90^{4}$, dispondo sobre a organização, o planejamento, a assistência e a articulação interfederativa no SUS. Busca viabilizar as condições para o estabelecimento de redes de atenção vinculadas a territórios delimitados (regiões de saúde) e, desse modo, avançar na universalidade, integralidade e igualdade da atenção.

\section{C) Saúde auditiva e equidade}

Conforme comentado anteriormente, o conceito de equidade empregado no presente artigo diz respeito à igualdade de direitos na prevenção das doenças e promoção da saúde. Dessa forma, as necessidades dos usuários vão muito além do acometimento auditivo. Os usuários e suas famílias vivem em situação de vulnerabilidade psicossocial e econômica, haja vista pertencerem a um grupo social apenas parcialmente coberto por políticas públicas mais amplas, como evidenciado no relato de um dos sujeitos. De acordo com uma das fonoaudiólogas:

Você tem familias que precisam de tantas outras coisas, que fazer escutar ou não é um mero detalhe. Familias muito carentes em muitas coisas. [...] a gente até arriscou dizer que mesmo se aquela criança fosse ouvinte, nem assim ela falaria. Porque não tem estímulo pra isso. [...] Muito grande são as dificuldades sociais dessas famílias, que muitas vezes moram em lugares violentos. Se você pergunta se ele escuta, a família responde: Ah, ele ouve sim! — Ouve? Ele ouve o quê? - Ah! Ele vive ouvindo barulho de tiro. Nossa! Isso dói ouvir. Mas é a realidade. O único som que ele escuta é o barulho de tiro e é o único som que a gente reza pra que os nossos filhos não escutem. (Fonoaudióloga 2)

A narrativa traduz a desvantagem que a desigualdade social oferece ao pleno desenvolvimento do potencial de saúde, pois problemas individuais e coletivos, objetivos e subjetivos interferem diretamente no êxito da reabilitação auditiva. Segundo Campos ${ }^{5}$ uma ação baseada na equidade precisa levar em consideração a singularidade da existência humana na aplicação das normas genéricas que, neste caso, diz respeito ao fornecimento de aparelhos auditivos.

Em função disso, os profissionais apontaram ser premente a atuação do psicólogo e da assistente social com o objetivo de qualificar o serviço. Há necessidade de conhecer profundamente o paciente, sua família e as condições de vida para oferecer um bom atendimento. Sabemos que a atuação desses profissionais por si só, não será capaz de transformar essa realidade, mas a atuação conjunta da equipe poderá encontrar formas de atenção mais produtivas, no sentido de mais adequadas às necessidades dessas famílias e crianças.

Segundo outra fonoaudióloga:

A gente precisava do serviço de psicologia nos auxiliando. Do serviço social também nos auxiliando na nossa adequação de conduta, se vamos protetizar agora ou não. Se é o momento certo ou não. Também não é só dizer: - 'Não te dou o aparelho agora'. Porque eles já foram negligenciados a vida inteira. A gente não pode ser negligente mais uma vez. Só que ao mesmo tempo é colocar um aparelho pra virar um brinco. A gente não pode colocar um aparelho sabendo que ele não vai ser usado. É doído também assim. A gente fica numa situação bastante delicada o tempo todo. Imagina só que bom seria se a gente fizesse: — 'Vamos fazer o seguinte [...] a gente continua acompanhando na audiometria, a gente continua acompanhando na otorrino, e vamos deixá-lo em acompanhamento com a psicóloga'. Vamos dar aí três meses pra gente verificar a partir de uma avaliação mais criteriosa. A gente tem um parecer mais fiel do que é essa emoção contribuindo ou não no tratamento dessa surdez. Daí eu acho que a gente poderia fazer um programa de SAÚDE (dá ênfase à palavra) auditiva de verdade. (Fonoaudióloga 2)

$\mathrm{Na}$ visão dos profissionais uma forma de garantir um atendimento não apenas mais equâ- 
nime, mas também mais integral, seria com a participação da assistente social e da psicóloga e com uma atuação interdisciplinar entre os profissionais, observando os sujeitos e suas necessidades como um todo e não apenas a saúde auditiva. Certamente, o olhar e o cuidado integrais fazem parte das atribuições de todos os profissionais de saúde, não cabendo apenas aos psicólogos e assistentes sociais esse papel. No entanto, a fala das fonoaudiólogas expressa uma demanda comum a profissionais de saúde que lidam com populações sob condições de vida muito difíceis, e diante das quais se sentem absolutamente impotentes. Nessas situações, uma tendência é supor que um outro estará melhor instrumentalizado para lidar com as dificuldades que expõem nossas próprias limitações e fragilidades. Mas, psicólogos e assistentes sociais, atuando em equipe com os demais profissionais, têm sim, muito a contribuir para a qualificação da atenção (desde que atuem de modo interdisciplinar, com os demais profissionais).

Para incorporar a equidade como um propósito a ser considerado no modo de atuação do serviço, é necessário priorizar a ação interdisciplinar adaptada à realidade dos usuários, buscando garantir a efetividade da atenção prestada.

Para tanto, Campos ${ }^{5}$ ressalta que os atores sociais precisam se sentir capazes de julgarem de forma justa cada situação singular e terem autonomia suficiente para assim nortearem suas ações de saúde.

\section{Considerações finais}

O trabalho mostrou que a universalidade, a integralidade e a equidade não estão plenamente contempladas no que se refere aos cuidados ofertados no serviço estudado, ou seja, nem todas as pessoas têm acesso ao serviço, o atendimento oferecido é fragmentado e com foco no acometimento auditivo, e as desigualdades sociais são pouco consideradas no momento da protetização.

Esses fatos indicam a importância de aprimorar a atenção para que, efetivamente, venha a atender as necessidades da população. Grande parte das dificuldades e limitações evidenciadas está relacionada à organização dos processos de trabalho, à gestão e à capacidade instalada. Desse modo, em tese, o setor saúde tem como atuar na melhoria dessas questões, pois detém o conhecimento técnico para superar vários dos entraves apontados no estudo, mas depende da disponibilidade de recursos financeiros e apoio político para implementar as mudanças organizacionais necessárias.

Investimentos relativamente simples em capacitação e qualificação profissional podem propiciar transformações em direção a um serviço mais universal, integral e equânime. Uma estratégia possível é o aprendizado da língua de sinais pelos profissionais e o oferecimento de espaços de discussão sobre os casos clínicos atendidos para ampliar as oportunidades de atuação interdisciplinar.

Com relação à igualdade/equidade, os constrangimentos transcendem o campo da saúde, mas cabe aos profissionais atuar no sentido da construção de estratégias conjuntas de ação, estabelecimento de alianças e articulações intersetoriais.

Políticas como a criação da Rede de Cuidados à Pessoa com Deficiência e o estabelecimento das Regiões de Saúde (como territórios que viabilizem a efetivação das ações de promoção, prevenção, tratamento e reabilitação), constituem iniciativas relevantes que podem contribuir para avançar na implementação de uma atenção à saúde auditiva da população brasileira mais universal, integral e equânime.

\section{Colaboradores}

NG Vianna, MLT Cavalcanti e MD Acioli participaram igualmente de todas as etapas de elaboração do artigo.

\section{Agradecimentos}

À Profa Dra Maria da Graça Garcia Andrade. 


\section{Referências}

1. Brasil. Constituição Federativa do Brasil de 05 de outubro de 1988. Diário Oficial da União 1988; 05 out.

2. Brasil. Decreto $\mathrm{n}^{\circ} 6.949$, de 25 de agosto de 2009 . Promulga a Convenção Internacional sobre os Direitos das Pessoas com Deficiência e seu Protocolo Facultativo, assinados em Nova York, em 30 de março de 2007. Diário Oficial da União 2009; 26 ago.

3. Brasil. Ministério da Saúde (MS). Portaria GM/MS no 2.073 , de 28 de setembro de 2004. Institui a Política Nacional de Atenção à Saúde Auditiva. Diário Oficial da União 2004; 28 set.

4. Brasil. Lei no 8080, de 19 de setembro de 1990 Dispõe sobre as condições para a promoção, proteção e recuperação da saúde, a organização e o funcionamento dos serviços correspondentes e dá outras providências. Diário Oficial da União 1990; 20 set.

5. Campos GWS. Reflexões temáticas sobre equidade e saúde: o caso do SUS. Saúde e Sociedade 2006; 15(2):23-33.

6. Brasil. Lei 7.853 , de 24 de outubro de 1989. Dispõe sobre o apoio às pessoas portadoras de deficiência, sua integração social, sobre a Coordenadoria Nacional para Integração da Pessoa Portadora de Deficiência (CORDE), institui a tutela jurisdicional de interesses coletivos ou difusos dessas pessoas, disciplina a atuação do Ministério Público, define crimes, e dá outras providências. Diário Oficial da União 1989; 25 out.

7. Brasil. Decreto no 3.298 , de 20 de dezembro de 1999. Regulamenta a Lei no 7.853 , de 24 de outubro de 1989. Dispõe sobre a Política Nacional para a Integração da Pessoa Portadora de Deficiência, consolida as normas de proteção, e dá outras providências. Diário Oficial da União 1999; $21 \mathrm{dez}$.

8. Fabrício MF. Da rede de atenção a rede de cuidados: o desafio da transformação. In: Bevilacqua MC, Martinez MAN, Balen AS, Pupo AC, Reis ACMB, Frota S, organizadores. Saúde Auditiva no Brasil: Políticas, Serviços e Sistemas. São José dos Campos: Pulso; 2010. p. 179-188.

9. Oliveira RF, Andrade LOM, Goya N. Acesso e integralidade: a compreensão dos usuários de uma rede de saúde mental. Cien Saude Colet 2012; 17(11):30693078.

10. Viana ALA, Fausto MCR, Lima LD. Políticas de saúde e equidade. São Paulo em Perspectiva 2003; 17(1):58-68.

11. Rio de Janeiro. Deliberação CIB-RJ no 560, de 13 de novembro de 2008. Estabelece parâmetros para a regulação estadual das consultas otorrinolaringológicas e avaliações para diagnóstico das perdas auditivas nos serviços habilitados na Rede de Atenção à Saúde Auditiva do Estado do Rio de Janeiro (média e alta complexidade). [acessado 2010 jan 29]. Disponível em: http://www.cib.rj.gov.br/deliberacoes-cib/ 116-cib-2008/novembro/455-deliberacao-cib-rj-n0560-de-13-de-novembro-de-2008. html
12. Brasil. Ministério da Saúde (MS). Portaria MS/SAS no 587, de 07 de outubro de 2004. Determina que as Secretarias de Estado da Saúde dos estados adotem as providências necessárias à organização e implantação das Redes Estaduais de Atenção à Saúde Auditiva. Diário Oficial da União 2004; 07 out.

13. Bardin L. Análise de Conteúdo. Lisboa: Edições 70; 1979.

14. Minayo MCS. O desafio do conhecimento: pesquisa qualitativa em saúde. 10a ed. São Paulo: Hucitec; 2007.

15. Amaral LS, Guilan MCR. A Politica Nacional de Atenção à Saúde Auditiva: avanços e entraves no município do Rio de Janeiro [dissertação]. Rio de Janeiro: Escola Nacional de Saúde Pública Sérgio Arouca; 2009.

16. Silva EJC, Llerena Júnior JC, Cardoso MHCA. Estudo seccional descritivo de crianças com deficiência auditiva atendidas no Instituto Nacional de Educação de Surdos, Rio de Janeiro, Brasil. Cad Saude Publica 2007; 23(3):627-636.

17. Ianni A, Pereira PCA. Acesso da comunidade surda à Rede Básica de Saúde. Saúde e Sociedade 2009; 18(2):89-92.

18. Nóbrega JD, Andrade AB, Pontes RJS, Bosi MLM, Machado MMT. Identidade surda e intervenções em saúde na perspectiva de uma comunidade usuária de língua de sinais. Cien Saude Colet 2012; 17(3):671-679.

19. Chaveiro N, Barbosa MA. Assistência ao surdo na área da saúde como fator de inclusão social. Rev Esc Enferm 2005; 39(4):417-422.

20. Grossi Junior R, Santos DAS. Utilização da Língua Brasileira de Sinais no atendimento aos surdos/deficientes auditivos como forma de humanização da enfermagem. Revista Virtual de Cultura Surda e Diversidade. [acessado 2010 maio 10]. Disponível em: URL: http://www.editora-arara-azul.com.br/revista/ compar4.php

21. Menicucci TA. Implementação da Reforma Sanitária: a formação de uma política. In: Hochman G, organizador. Políticas Públicas no Brasil. Rio de Janeiro: Ed. Fiocruz; 2007. p. 303-325.

22. Cecílio LCO. As necessidades de saúde como conceito estruturante na luta pela integralidade e equidade na atenção em saúde. In: Pinheiro R, Mattos $\mathrm{R}$, organizadores. Os sentidos da integralidade na atenção e no cuidado à saúde. Rio de Janeiro: IMS/ UERJ, Abrasco; 2001. p. 113-126.

23. Chaveiro N, Barbosa MA, Porto CC. Revisão de Literatura sobre o atendimento ao paciente surdo pelos profissionais da saúde. Rev Esc Enferm 2008; 42(3):578-583.

24. Freire DB, Gigante LP, Béria JV, Palazzo LS, Figueiredo ACL, Raymann BCW. Acesso de pessoas deficientes auditivas a serviços de saúde em cidade do Sul do Brasil. Cad Saude Publica 2009; 25(4):889897. 
25. Barbosa MA, Oliveira MA, Damas KCA, Prado MA Língua Brasileira de Sinais: um desafio para a assistência de enfermagem. Rev Enferm UERJ 2003; 11(3):247-251.

26. Fundação Oswaldo Cruz (Fiocruz). A saúde no Brasil em 2030: diretrizes para a prospecção estratégica do sistema de saúde brasileiro. Rio de Janeiro: Fiocruz, Ipea, Ministério da Saúde, Secretaria de Assuntos Estratégicos da Presidência da República; 2012.

27. Brasil. Ministério da Saúde (MS). Portaria GM/MS no 793, de 24 de abril de 2012. Institui a Rede de Cuidados à Pessoa com Deficiência no âmbito do Sistema Único de Saúde. Diário Oficial da União 2012; 25 abr.

28. Brasil. Decreto no 7.612 , de 17 de novembro de 2011. Institui o Plano Nacional da pessoa com Deficiência - Plano Viver sem Limite. Diário Oficial da União 2011; 18 nov.

29. Brasil. Decreto no 7.508, 28 de junho de 2011. Regulamentação da Lei no 8.080 . Dispõe sobre a organização, o planejamento, a assistência e a articulação interfederativa no SUS. Diário Oficial da União 2011; 29 jun.

Artigo apresentado em 14/06/2013

Aprovado em 20/08/2013

Versão final apresentada em 27/08/2013 